\title{
Kahraman Odaklı Yapısal Halkbilimi Kuramlarına Göre Kürt Halk Anlatılarından Çîroka Sultan û Wezîr
}

\section{Ferhat ÇiFTÇi'}

\section{Öz}

Dilsel ve kültürel ögelerin toplumlar nezdinden önemli bir yeri olduğu malumdur. Toplumlar, bu ögeler sayesinde yaşamlarını devam ettirecek gücü kendinde bulur. Söz konusu ögeler, halk yaşantısının çeşitli ürünleri olarak başlangıçtan bu yana sözlü gelenekle var olmuștur. Sonrasında bunlar, yazılı gelenek içinde de somut bir karşılık göstermiştir. Halk anlatıları, bunlardan olup barındırdığı unsurlarla kültürel dokuyu çeşitli açılardan resmetmektedir. Bu çerçevede kahraman figürü, halk anlatılarında ön plana çıkan ve temsil gücü yüksek olan kültürel değerlerden sayılır. Kimi halk anlatılarında kahramanın yiğitliği ve kurtarıcı rolü; kiminde ise onun üzerinden iletilmek istenen ahlaki dersler baskınlık gösterir. Bu cihetle halk anlatılarının mekânsal ve kültürel farklııkları yanında evrensel özelliklere sahip bulunduğu da ileri sürülmüştür. Zaman içinde halk bilimi çalışmalarında kahramana odaklanan ve ortak yapısal ilkeler ileri süren kuramlar gelişim göstermiştir. J. G. Von Hahn'ın “Aryan Kahramanı Biyografik Modeli”, Otto Rank'ın "Kahraman Kalıbı”, Lord Reglan'ın “Geleneksel Kahraman Kuramı” ve Eric J. Hobsbawn'ın “Sosyal Haydut" veya "Kahraman Kalıbı" halk anlatılarındaki kahramanların metin merkezli olarak incelendiği kuramlardandır. Nitekim araştırmacılar tarafından bu kuramlar dikkate alınmıs, incelenen halk anlatılarında kahramanların özellikleri yapısal olarak belirlenmeye çalışııış̧ır. Bu araştırmada bir Kürt anlatısı olan Çîroka Sultan û Wezîr, barındırdığı karşılıklar itibarılya ilgili kuramlardan üçüne göre incelenmiş ve anlatının yapısal anlamda gösterdiği denklikler tespit edilmeye çalışıımışır.

Anahtar Kelimeler: Halk Anlatıları, Kahraman Odaklı Yapısal Halk Bilimi Kuramları, Çîroka Sultan û Wezîr, Yapısal Denklikler.

\footnotetext{
1 Dr. Öğr. Üyesi, Muş Alparslan Üniversitesi, Sağlık Hizmetleri MYO, Çocuk Bakımı ve Gençlik Hizmetleri Bölümü, ferhatciftci1@gmail.com, ORCID: 0000-0003-4117-2477.
} 


\title{
The Kurdish Narrative Sultan u Wezir According to the Hero- Oriented Folklore Theories
}

\begin{abstract}
It is known that linguistic and cultural elements have an important role in the eye of the communities. The communities lead a life by means of these elements. The aforementioned elements have been existing as various products of the folk life by oral tradition from the beginning. These elements, then, have had a written tradition as well. Folktales are of the written tradition and depict the cultural texture from various aspects by its elements. Within this framework, the hero figure is considered as one of the cultural values that stands out in the folktales and has a strong representative power. In some folktales, the bravery of the hero and his savior role are dominant while in others ethical values which are aimed to be delivered via the hero predominate. Hence, it is suggested that the folktales have universal characteristics as well as spatial and cultural differences. Over time, theories focusing on the hero in folklore studies and suggesting common structural principles have developed. J. G. Von Hahn's Aryan Hero Biographical Model, Lord Reglan's Traditional Hero Theory and heroes in folk narratives are among the theories that are examined as text-centered. As a matter of fact, these theories were taken into consideration by the researchers, and the characteristics of the heroes were tried to be determined structurally in the folk narratives examined. In this study, Çîroka Sultan û Wezîr, a Kurdish narrative, was examined according to three of the related theories in terms of its responses, and the structural equivalents of the narrative were tried to be determined.
\end{abstract}

Keywords: Folk Narratives, Hero-oriented Structural Folklore Theories, Çîroka Sultan û Wezîr, Structural Equations.

\section{Extended Abstract}

One of the important determinants of the individual and society is the hero figure. The hero is in the focal point, recalling the common bonds of societies for both traditional and modern times and uniting their desires. In this respect, it has responses that transcend the individual level and are attributed to various meanings. This situation varies as heroes for mythology, prophets for religions, and idols for ideologies. Carlyle (2000: 13) states that the hero is a subject as wide and limitless as world history, and examines the characters of heroes as god, prophet, poet, clergyman, writer and king. The existence of societies in history has been possible by protecting linguistic and cultural elements. Linguistic and cultural elements bring to mind the oral tradition at first, and then both oral and written tradition, taking their source from the folk life. According to Pertev (2018: 64), there is a strong link between folklore and national identity, and for three centuries, folklore products have functioned in the establishment, maturation and change of national identity. According to 
Zana (2019: 58-59), folklore is a treasure for peoples, and a nation without folklore is undated and unfounded. Folk narratives are an important component of the structure aforementioned and are mostly woven around the heroes. At this point, it is necessary to read the heroes in folk narratives as important symbols identified with the struggle for existence, preferences and behavior of nations. As a matter of fact, Bozkoyun (2015: 143), who examines fairy tales, states that although the themes of Kurdish fairy tales are composed of imaginary elements, social life basically takes place. He mentions that the Kurds have expressed their hopes and feelings thanks to their folk songs and fairy-tale heroes. The hero figure, which has important responses in their lives due to the social structure of societies, may change depending on generic factors for folk narratives. Sometimes, what an epic hero achieves, in this respect, a fairy-tale hero can also do. In fact, it can be said that the aforementioned narratives have a dynamic structure in the public memory, which has an effect on this. As a matter of fact, folk narratives have always been open to possible changes with different variants and transitions. However, this multidimensionality and the folk narrative material that makes it possible show similarities in some respects with the narratives of different peoples. Campbell (2010: 48) explains the hero-oriented similarities regarding folk narratives with the idea of unity in some aspects of humanity. These similarities make it possible to mention certain criteria, especially through the text. The responses of text-centered readings mostly arise from this point. Herooriented structural folklore theories focus on the biography of the hero in a text-centered manner. Çobanoğlu (2012: 207) states that the first study on the way of formulating the lives of heroes in folk narratives and revealing their structure was done by the German folklorist Johann Georg Von Hahn in 1864. In this context, he examines VonHahn's Aryan Hero Biographical Model, Otto Rank's Hero Pattern, Eric Hobsbawn's Social Bandit or Hero Pattern, and LordRaglan's Traditional Hero Pattern under the heading of hero-oriented theories of structural folklore. Apart from the hero's biography, other theories of structural folklore are the methods of Vladimir Propp and Claude Lévi Strauss. Hîkmet (2015: 74) points out that the theories of structural folklore differ in two ways and that Propp and Strauss focus on the functions of the text rather than the hero. It should be considered that structural folklore theories have limiting dimensions as well as their benefits or facilitating effects. The evaluation of folk narratives with strong cultural equivalents within these drafts prepares the ground for covering or omitting their private sides. Moreover, it is inevitable that approaching cultural diversity with patterns will create some difficulties. Even considering the fact that there are many variants of a single folk narrative makes variations possible. In this respect, it is important to consider the results of the studies that will be made within the framework of the mentioned examination methods. In some studies on folklore narratives based on related theories, some concerns were expressed in this direction. In the study conducted by Tarduş (2018: 74-75), the Kurdish narratives named Xanê Çengzêrîn, Zembilfiroş, Memê Alan, Ferxik, Cembelî, DewrêșêEvdî, Kulik and Siyabend were examined according to Raglan's theory and it was determined that the similarities 
were limited. Thereupon, it was attempted to create independent structures for these narratives. Çîroka Sultan û Wezîr, one of the Kurdish folk narratives, draws attention as a fairy tale in which short passages are intertwined. Vizier intends to teach the Sultan a lesson, who does not want to come to reason during the narration. As the vizier narrates, the focal point varies and people gain importance accordingly. Although the Kurdish narrative named Çîroka Sultan û Wezîr does not fully comply with the principles of hero-oriented structural folklore theories, it is in conformity with some principles of these theories. In this respect, there is neither a complete structural harmony nor a complete distance between the principles determined for Western narratives and the sample narrative. As a matter of fact, some items of text-centered and hero-oriented structural folklore theories taken into consideration in the research allow the establishment of direct or indirect concerns. The narrative was considered to be associated with six of the sixteen principles in total, which are named as the Birth, Youth, Return and Second Order titles of Johann GeorgvonHahn's Aryan Hero Biographical Model. It has been determined that nine of the 12 principles found in Otto Rank's Hero Pattern have an overlap. It has been found that the narrative is compatible with only six of the twenty-two principles of LordRaglan's Traditional Hero Theory. This result shows that, in the example of Çîroka Sultan û Wezîr, one of the Kurdish narratives, folk narratives have both some commonalities and privatizations in terms of structural elements. 


\section{Giriş}

Birey ve toplum arasında önemli belirleyenlerden biri kahraman figürüdür. Kahraman, hem geleneksel hem de modern zamanlar için toplumların ortak bağlarını hatırlatan ve arzularını kendinde birleştiren odak noktasında yer alır. Bu yönüyle bireysel düzlemi aşan ve çeşitli anlamlar atfedilen karşılıklara sahiptir. Bu durum, mitoloji için kahramanlar, dinler için peygamberler, ideolojiler için ise idol olarak değişkenlik gösterir. Carlyle (2000: 13), kahramanın dünya tarihi kadar geniş, sınırsız bir konu olduğunu belirtir ve kahraman tiplemelerini tanrı, peygamber, kral, din adamı, şair ve edebiyatçı olarak irdeler. Dikkat edilirse bunlar, liderlik kavramı etrafında toplumlar için kaçınılmaz bir yapı olarak belirir. Daha doğrusu kahramana yüklenen anlamlar ve onu karşılama biçimi farklılık gösterse de sembol şahsiyetler adından hep söz ettirir. Bunların yerine ikame edilecek farklı değerler ve unsurlar da temsilî bir özellik gösterir. Bu bakımdan kahramana, genel olarak sosyal yapının kendini var etme ve gösterme sembolü olarak bakmak mümkündür.

Toplumların tarih içerisinde varlıkları, dilsel ve kültürel ögelere sahip çıkmakla mümkün olmuştur. Dilsel ve kültürel ögeler, kaynağını halk yaşantısından alarak başlangıçta sözlü, daha sonra da hem sözlü hem de yazılı geleneği akla getirmektedir. Pertev'e (2018: 64) göre folklor ve millî kimlik arasında güçlü bir bağ vardır ve üç yüzyıldır folklor ürünleri millî kimliğin tesisi, olgunlaşması ve değişiminde işlev görmektedir. Zana'ya (2019: 58-59) göre de folklor halklar için bir hazinedir ve folkloru olmayan bir millet tarihsiz ve asılsızdır. Halk anlatıları, söz konusu yapının önemli bileşenlerindendir ve çoğunlukla kahramanlar etrafında örülmüştür. Bu noktada halk anlatılarındaki kahramanları, milletlerin varlık mücadelesi, tercihleri ve davranış biçimleriyle özdeşleşmiş önemli semboller olarak okumak gerekir. Nitekim masalları irdeleyen Bozkoyun (2015: 143), Kürtçe masalların konularını hayalî unsurların oluşturmasına karşın temelde toplumsal yaşamın yer aldığını belirtir. Kürtlerin türkü ve masal kahramanları sayesinde umutlarını ve duygularını dile getirdiğinden bahseder.

Toplumların sosyal yapı gereği hayatlarında önemli karşılıklar barındıran kahraman figürü, halk anlatıları için türsel etkenlere bağlı olarak değişebilmektedir. Bazen bir destan bazen de bir masal kahramanı yüceltilen değerlere ulaşmak adına ön plana çıkmaktadır. Söz konusu anlatıların halk belleğinde dinamik bir yapıda olması, kimi zaman bunların birbirinin yerine anılmasını beraberinde getirmektedir. Bu açıdan halk anlatıları, farklı varyant ve geçişlerle muhtemel değişimlere hep açık olmuştur. Fakat yine de bu çok boyutluluk ve buna imkân hazırlayan halk anlatısı malzemesi, farklı halklara ait anlatılarla kimi açılardan benzerlik göstermektedir. Campbell (2010: 48), halk anlatılarına ilişkin olarak kahraman odaklı benzerlikleri, insana dair bazı hususlardaki birlik fikri ile izah eder. Bu benzerlikler, özellikle metin üzerinden belli kriterlerin söz konusu edilmesine olanak sağlamaktadır. Metin merkezli okumaların, barındırdığı karşılıklar daha çok bu noktadan ileri gelmektedir. 
Halk anlatılarına ilişkin metin merkezli okumalar sunan kuramlar, kahramanın çözümlenmesi için kendi dayanakları çerçevesinde bazı ilkeler ileri sürmektedir. Bu ilkelerin kahraman kalıbına yönelik belirlemeleri, aynı zamanda halk muhayyilesinin işaretlerini taşımaktadır. Muayyen bir yapı olarak beliren halk anlatıları, ortak ilklerde buluştukça bunlar arasında bazı bağların olduğu anlaşılmaktadır. Böylece halk anlatılarına dair hem yerel hem de evrensel ilgilerin kurulabileceği bir söyleme varmak olanaklı hâle gelmektedir. Nitekim söz konusu ilgileri, halk anlatıları üzerine yapılan bazı tetkiklerden görmek mümkündür. Kahraman etrafında şekillenen metinlerin yapısal anlamda bazı benzerlikler gösterdiği, ileri sürülen kimi ilkelerle uyuştuğuna dair tespitler, bu tetkiklerin vardığı en genel sonuçlardandır.

Başka bir açıdan bakacak olursak herhangi bir anlatının insan belleğinde özel ve genel bazı karşılıklara denk gelmesi doğal bir durumdur. Eliade (2001: 15), bunu, mitin çok sayıda ve birbirini tamamlayacak nitelikte olan bakış açılarına göre işlenip yorumlanabilen oldukça karmaşık bir kültür gerçekliği şeklinde izah eder. Bu izah çerçevesinde söylenecek olursa halk anlatısı ve malzemesinin benzeşen ve ayrışan algı ve yorumlara açık olması, kuramsal çerçevenin şekillenmesine de, analiz yöntemlerinin tercihlerine de etki ettiği gerçeğiyle karşılaşılır.

Bu araștırmada bir Kürt anlatısı olan Çîroka Sultan û Wezîr'e kahraman odaklı yapısal halk bilimi kuramları çerçevesinde odaklanılmıştır. Araştırmanın sınırılığını, söz konusu anlatı ve incelemede esas alınan kuramlar oluşturmaktadır. Nitel araştırma yöntemlerinden doküman incelemesi ve betimsel analizin kullanıldığı araştırmada, elde edilen bulgular kuramların ilkelerine göre yorumlanmıştır. Anlatıya bakıldığında "Sosyal Haydut" veya "Kahraman Kalıbı" dışında söz konusu halk bilimi kuramlarından bazı maddelerle denkliklere sahip olduğu anlaşılmaktadır. Dolayısıyla bu araştırma, örnek olarak seçilen halk anlatısının ilgili kuramlara göre hangi açılardan benzerlik taşıdığını veya ayrıştığını amaçlamakta olup bazı dikkatleri söz konusu etmektedir. Araştırma, bu amaç doğrultusunda Kürt halk anlatılarından örnek bir masalın kahramanının farklı kuramlara göre konumlandırıması ve anlamlandırıması açısından önem taşımaktadır.

\section{Kahraman Odaklı Yapısal Halk Bilimi Kuramları}

Kahraman odaklı yapısal halk bilimi kuramları, metin merkezli olarak kahramanın biyografisine odaklanır. Çobanoğlu (2012: 207), halk anlatılarındaki kahramanların yaşamlarının formüle edilmesi ve yapısının ortaya koyulması amacıyla ilk çalışmanın Alman halkbilimci Johann Georg Von Hahn tarafından 1864 yılında yapıldığını belirtir. Bu çerçevede Von Hahn'a ait “Aryan Kahramanı Biyografik Modeli”, Otto Rank'ın ortaya koyduğu “Kahraman Kalıbı”, Eric Hobsbawn'a ait "Sosyal Haydut" veya "Kahraman Kalıbı" ve Lord Raglan'a ait "Geleneksel Kahraman Kalıbı"'nı kahraman odaklı yapısal halk bilimi kuramları başlığı altında irdeler. Kahramanın biyografisi dışında diğer yapısal halk bilimi 
kuramları ise Vladimir Propp ve Claude Lévi Strauss'un yöntemleridir. Hîkmet (2015: 74), yapısal halk bilimi kuramlarının iki yönlü olarak ayrıldığına değinerek Propp ve Strauss'un kahramandan ziyade metnin fonksiyonlarına odaklandığına dikkat çeker. Fakat Subaşı'nın (2019: 92) işaret ettiği üzere Propp'un belirlediği yedi işlev alanı karakterler ve kahraman üzerine bina edilmiştir. Dolayısıyla işlev ve onu gerçekleştireni ayırmak bu açıdan pek de mümkün değildir. Öte yandan Propp, Masalın Biçimbilimi adlı eseriyle sosyal ve beşerî bilimlerde yapısalcılığın yaygınlaşması sürecinde öncülük etmiştir ve metin çözümleme yöntemlerinin gelişmesinde rol oynamıştır (Dündar, 2002: 118; Çobanoğlu, 2012: 214).

Çobanoğlu (2012: 207), yapısal inceleme yöntem ve kuramlarının bütünün amacının halk bilim türlerini evrensel modellere ve formüllere indirgenerek belirlemek olduğunu söyler. Bu amaç doğrultusunda oluşacak bir folklor grameriyle evrensel ölçekte mukayeseli çalışmaların daha da kolaylaşmasının düşünüldüğünden bahseder. Ayrıca yapısalcılığın halk bilimine sunduklarını, A. Dundes'ten üç maddeyle aktarır:

a) Tür teorisi, türlerin tanımlanmasında geçerli kriterler sunması.

b) İleri sürülen tezlerin kolaylıkla başka kültürlerden malzemeye uygulanabilir veya geçerliklerinin test edilebilir olması.

c) Bu özellikleri nedeniyle halk bilimcilere çalışmalarında daha somut bir objektif çalışma vasatı ve aracı oluşturması.

Yapısal halk bilimi kuramlarının sunduğu yararlar veya kolaylaştırıcı etkilerin yanında sınırlayıcı boyutları olduğunu da düşünmek gerekir. Kültürel karşılıkları güçlü olan halk anlatılarının bu taslaklar içerisinde değerlendirilmesi, onların özel taraflarının da örtülmesine ya da atlanmasına zemin hazırlar. Kaldı ki kültürel çeşitliliğe kalıplar eşliğinde yaklaşmanın kimi güçlükler doğurması kaçınılmazdır. Tek bir halk anlatısının birçok varyantının bulunduğu gerçeğini dahi düşünmek değişkenlikleri muhtemel kılmaktadır. Bu bakımdan yapılacak çalışmaların vardığı sonuçların söz konusu inceleme yöntemleri çerçevesinde düşünülmesi önem taşımaktadır. Nitekim ilgili kuramları esas alan halk bilimi anlatılarına yönelik bazı incelemelerde bu yönde kaygılar dile getirilmiștir. Tarduş'un (2018: 74-75) yaptığı incelemede Xanê Çengzêrîn, Zembilfiroş, Memê Alan, Ferxik, Cembelî, Dewrêşê Evdî, Kulik ve Siyabend adlı Kürt anlatıları Raglan'ın kuramına göre irdelenmiş, benzerliklerin sınırlı olduğu tespit edilmiştir. Bunun üzerine söz konusu anlatılar için bağımsız yapılar oluşturulmaya çalışılmıştır. Çeliktaş (2018: 82) da, Joseph Campbell'in kahraman teorisi ışığında Rustemê Zal ve Memê Alan anlatılarını incelemiş ve kahramanların serüvenlerinde benzeşmeler ve farklılaşmalara rastlandığına dikkat çekmiştir.

Çobanoğlu (2012: 207), kahraman kalıbına ilişkin çalışmaların neredeyse halk bilimi kadar eski olduğunu belirtir. Bu aslında toplumsal yapının pek çok örnekten anlaşılacağı üzere liderlik kültüne dayalı güçlü bir görünüme sahip olduğunu da ortaya koymaktadır. Bugün de birey ve toplumların farklı 
kulvarlarda birçok açıdan kahraman, lider ve öncülere bağlı tercihler ve davranışlarda bulunduğu aşikârdır. Edebî metinlerde kahraman tipinin çağın koşulları ve beklentilerine göre şekillendiği de bir gerçektir. Fakat yine de modern anlatılarda kahraman belirleyici konumdadır ve söylemi besleyen başat unsurlardan sayılmaktadır. Bu açıdan geçmişten bugüne kahraman toplumsal hafıza, kültürel yüklenimler, beklentiler ve değerler nezdinde önemli bir yer edinmiştir. Halk anlatılarında ise bunun güçlü bir karşılığa sahip olduğu bilinmektedir. Bu, kahramanın kurmaca özellikler taşıması durumunda bile etkisini yitirmeyecek bir anlam taşımaktadır.

Kahraman odaklı yapısal halk bilimi kuramlarından Johann Georg Von Hahn'ın “Aryan Kahraman Biyografik Modeli” “doğum, gençlik, dönüş aşamaları ile ikinci dereceden şahıslar" kategorilerinde toplamda on altı maddeden oluşmaktadır. Otto Rank'ın ortaya koyduğu “Kahraman Kalıbı”'nda toplamda on iki madde bulunmaktadır. Lord Raglan'ın “Geleneksel Kahraman Kuramı” ise toplamda yirmi iki madde içermektedir (Çobanoğlu, 2012: 208-2011). Eric Hobsbawn'ın kuramı “Sosyal Haydut" veya “Kahraman Kalıbı"'na ise inceleme metninde bir karşılığa sahip olmadığı için çalışmada yer verilmemiştir.

\section{2. Çîroka Sultan û Wezîr}

Kürt halk anlatılarından Çîroka Sultan û Wezîr, kısa aktarımların iç içe geçtiği bir masal olarak dikkat çeker. Anlatının öğretici ve düşündürücü özellikleri bünyesinde taşıdığı söylenebilir. Anlatı boyunca yola gelmek istemeyen Sultan'a, Vezir'i ders verme niyetindedir. Vezir anlattıkça odak noktası değişkenlik gösterir ve kişiler buna göre önem kazanır. Yalnız bütün anlatıyı kuşatan temel husus ise Sultan'ın ders çıkarması bağlamında Xortê Bedew'in (Yakışıklı Genç) kendisine biçilen role doğru yol almasıdır. Subaşı (2019: 72-74), masal kahramanlarının tespitinin kesinlik içermediğini ve çeşitli unsurların esas alınmasıyla anlatılarda kahramanın belirlenmesine dair farklılıklar olabileceğini hatırlatır. Bu anlatıda Sultan ön planda olmakla birlikte Vezir ile giriștikleri eylemlerin tümü Xortê Bedew'de konumlanır. Dolayısıyla çalışmada Sultan, değişim durumu ile karakter; Xortê Bedew ise eylem boyutu ile kahraman olarak belirlenmiştir. Anlatı, masal türleri içerisinde gerçekçi ve bağlı masallar kategorisinde değerlendirilebilir. Keskin (2019: 219, 220), gerçekçi masalların (çîrokên rasteqîn) kahramanlarının padişah, vezir, ağa, çoban vb. olduğunu; bağlı masalların (çîrokên formuleyî/zincireyî) ise birbirine sayı, anlatma ve olaylarla bağlı bulunduğunu belirtir. Çîroka Sultan û Wezîr'de karakterler ve biçim söz konusu unsurların olduğunu gösterir.

Masallarda karakterlerin iyi ve kötü olarak rollerini sürdürdükleri veya sona doğru değişim gösterdiğinden bahsedilebilir (Bozkoyun, 2015: 153). Örnek anlatıda Sultan, sona doğru iyi rolde bir değişim durumuyla sunulur. Tabii ki bu hemen gerçekleşmez ve hikmetli bir sonuç çıkarmak serüvene bağlı olarak sağlanır. Illkin ayak direyen ve tutumunda değişim göstermeyen Sultan, nihayetinde kahraman için kurgulanan olumlu durumun gerçekleşmesinde rol 
alır. Bu noktada Vezir, anlatıcı ve dolayısıyla yönlendirici; Xortê Bedew ise amaca ulaşmanın ve olumlu sonucun adresi konumundadır. İç hikâyelerin sonucunda Sultan'ın şahsında okurdan ve dinleyicilerden tipik Doğu tarzı bir kıssadan hisse mantığına varması beklenir. Bu araştırmada metnin yapısal unsurlarına odaklanıldığından bu tarz bir söylemden kaçınılmıştır. Çiroka Sultan û Wezîr, Adîl Başaran tarafından aşağıda yer aldığı şekliyle aktarılmıştır (Cewerî, 2018: 65). Anlatının Türkçe çevirisi ise yazar tarafından yapılmış olup çalışmanın sonunda ekte yer almakadır:

Wezîrê wî bi destê wî digire û dibêje; "ka ji vê ramana xwe biqere, ger tu li min guhdarî bike, ez ê ji te re qala sultanekî bikim ku ew jî mîna te enirîbû û paşê ji wan kirinên xwe poşman bûbû"

Sultan bi wezîrê xwe re derdikeve nava gel û digere. Piştî gera çend bajaran, li wan dibe êvar. Hema li deriyê kê dixîne û dema derî vedibe ji xwediyê malê re dibêje;

"Hûn mêvanan vedihewînin" li ser vê xwediyê malê bersivê dide û dibêje:

- Mêvan mêvanê Xwedê ne, ser seran û çavan kerem ke hundir.

Zilamê malê ne sultan û ne jî wezîr wî nas dike! Piştî şîvê dibe derengiya şevê, cihê wan yê razanê radixe û radizên. Di wê şevê de pîreka male (kevanî) Xwedê kurekî didiyê. Li ser vê, li wezîr eyan dibe ku ev kurê nû hate dinê dê bibe qismetê qîza sultan!.. Wezîr serê sibehê tiştê bi şev lê eyan bû bi sultan re parve dike û dibêje:

- Îşev kurekî vê malê çêbû û kurê vê malê dê bibe qismetê qîza te.

Sultan li ser vê gelekî dienire û dibêje:

- Ez nahêlim ku kurê vê mala feqîr û belengaz bibe zavayê min.

Sultan, bangî bavê zarokê ku nû çêbûyî dike û dibêje:

- Heger tu vî kurê xwe bide min, ez ê sed zêrî bideme te.

Li ser vê bazara, hevserê jinikê bi hevala xwe re parve dike. Ji ber ku gelekî xizan bû vê xwestekê erê dike. Kurê xwe bi berdêla sed zêrî didine sultan. Sultan û wezîrê xwe radihêjin zarok û li cem xerat sindoqekê çêdike û dixin hundirê wê û dibe davêjin nava deryayê. Dema vedigere malê di rê de ji wezîrê xwe re dibêje:

- Min negot ku ez nahêlim ev zarokê feqîr û belangaz bibe qismetê keça min?

Pîştî demekê li bajarekî mirovekî ku debara xwe bi girtin û firotina masiyan dikir diçe ser deryayê masî girtinê, dema çav li sindoqê dikeve, hema kincên xwe ji xwe datîne û dikeve nava avê û radihêje 
sindoqê. Sindoqê dibe mal û derê wê vedike! Dibîne ku zarokekî çiqas bedew di hundirê wê sindoqê de derdikeve. Ji ber ku zarokên wan jî tunebû gelekî bi wî zarokî şa dibin. Masîgir û hevsera xwe zarok mîna ku yê wan be xwedî kir û mezin kirin. Piştî bi salan xortekî gelek bedew û jîr û zana jê derket. Dema bavê wî masî digirt, wî jî dibir li bazarê difirot û diravê xwe dianî dida bavê xwe. Berî her kesî masîfiroşan wî masiyê xwe xilas dikir, gelekî jîr û zana bû, her kesê dihatin bazarê ji wî masî dikirîn. Gelek dem û dewran bihurî, rojekê wezîrê Sultan riya xwe bi bazarê dixîne. Dema diçe û çavli wî xortê bedew dikeve hema wî di cih de nas dike. Vedigere û ji Sultan re vedibêje.

- Ez qesem dikim bi navê Xwedê, min îro ew zarokê me berda nava deryayê li bazarê dît. Li ser vê bi pey wî dikevin û diçin malê ku lê dimîne. Li derî dixîne, derî vedike û dikevin hundir. Xwediyê malê wan nas nake û dipirse: "Hûn kî ne û çi dixwazin?" li ser vê pirsê Sultan dibêje:

- Em hatine ji bo xortê ku te mezin kiriye, ew ne yê te ye, em hat wî ji te bistînin, tê bide me, li hemberî xwedîderketina te û keda we, ez ê xelateke giranbaha bidim. Li ser vê, masîgir fêm kir û bangî hevsera xwe kir.

Piştî mêrik bi jina xwe re ev vegot û ji ber ku ew rastî jî bû ne kurê wan bû, bi bêdilî be jî qebûl kir û ew xelatadayin pejirand û bi destê wî girt û da destê Sultan. Zêrê wî dayê.

Sultan nivîsek nivîsî û da destê xortê bedew û jê re got:

- Tu yê vê peyamê ji vê navnîşanê re bibe hetanî ku em tên.

Xortê ciwan û bedew radihêje peyama Sultan û berê xwe dide bajarê mezin û diçe. Bi rojan dimeşe xwe digihîne bajêr gelekî westiyayî ye li rex bajêr, li nava rezekî li ber darekê radiweste. Li binê darê rûdine û di xew de diçe.

Di wê navberê de, qîza Sultan jî ji serayê derdikeve û diçe li nava baxçe digere. Dema li nava baxçe digere dibîne ku mirovek li binê darê di xew de ye. Diçe nêzî ku li çi mêzeke! xortekî ciwan û mîna heyva çardehî, xortekî sipehî û bedew evîndarî wî dibe. Di destê wî de wê peyamê dibîne bi hêdîka ji nava destê wî derdixe û vedike. Qîza Sultan nîvîsa bavê xwe nas dike û tê de gotiye:

- Ji celadan re, ger ev xort hate cem we, hûnê tu tiștî jê nepirsin û serê wî jê bikin. 
Li ser vê nivîsê, qîza Sultan dike niç niç û di dilê xwe de dibêje "Gelo bavê min çi ji vî xortê bedew xwestiye?" Qîza Sultan nivîseke din dinivîse û tê de wiha dibêje:

- Ji celadan re, ger ev xort hate cem we, hûnê berî ku ez bigihêjim bajêr, bi qîza min re bizewicînin.

Û wê nivîsa bavê xwe diçerîne, ya wê nivîsandiye, dixe nava destê wî û bi şûnde vedigere serayê... Piştî ku xortê bedew têr xewa xwe distîne û berê xwe dide wê navniş̧anê, diçe ber derî û nîvîsa di destê xwe de dide wê navnîşanê. Dema li nivîsê mêze dikin, hema bi zû radibe û xort bi xwe re dibe serayê û bi qîza Sultan re dide nasîn û amedekariya daweta wan dike.

Dema Sultan bi aramî tê bajêr ku li çi rast bê! Destê qîza wî di destê wî xortî de û li cihê ku amedekariya zewacê dike, li ser vê hêrs dibe û dibêje:

- Ez ê wî bi destê xwe bikujim! Min sond xwariye ku ev xort nebe qismetê qîza min.

Li ser vê hêrsa wî, Wezîrê wî bi destê wî digire û dibêje; "Ka ji vê ramana xwe biqere, ger tu li min guhdarî bike, ez ê ji te re qala sultanekî bikim ku ew jî mîna te enirîbû û paşê ji wan kirinên xwe poşman bûbû û êdî nema tiştên xirab kiribû û ji wan şaşitiyên xwe bi şûnde vegerîya.

Bila ev nêye serê te jî û wiha dom kir û got:

- Sultanê min, li welatekî sultanekî mîna te hebû, êvarekê teyrekî şitlek di nava niklê wî de anî û avête hewşa wî. Sultan jî ew şitla çand, dema bû serê sibehê, sultan derket hewşê, dît ku ew şitla mezin bûye û sêvên zahf girs pêve hatine. Bangî xulamê xwe kir û got here sêvekê bîne bê ev çi elemet e. Dema xulam diçe sêvekê li binê darê li erdê radihêje û tîne hinda sultan. Bangî dapîrekê dike û wê sêvê bi wê dide xwarin, hema di cih de dapîr dimire, li ser vê sultan gelekî dienire û xwe li ber teyr datîne. Ber êvarê cardin teyr tê û sultan teyr dikuje! Sultan difikire, paşê bangî xulamê xwe dike û dibêje te ew sêva ji ku anî li ser vê pirsê xulam dibêje "Min ew sêv li binê darê dît û min rahijtê.' Cardin sultan ji xulamê xwe re dibêje, here sibê ji darê jê bike û bîne. Dibe sêbe, sêva ji darê jêdike, dide yekî kal, çawa ku yê kal sêvê dixwe û bi xwarina sêvê re temenê wî vedigere mîna yê ciwanekî hivdeh salî. Li ser vê sultan zaf bi kuştina teyr poşman dibe." Sultanê min ger tu jî zavê xwe bikujî, tu ê jî poşman bibî.

Bi vê jî sultan îkna nabe. Wezîrê wî çîrokeke din vedibêje û dibêje: 
- Sultanê min, yekî din jî hebû rojekê diçe nêçîê. Gelekî li çol û çiyan digere. Zaf diweste, tî dibe, lê li tu deran avê peyde nake. Diçe ber zinarekî, bala xwe dide ku ji wî zinarî dilopên avê ji jor de dikeve erdê, hema tasika xwe ji cuherê xwe derdixe û dide ber wan dilopên ku ji jorde dikeve! Dema dikire vexwe teyrê wî baskê xwe li tasê wî dixe û wê ava ku ketibû tasê dirijîne.

Piştî çend caran cardin teyrê wî baskên xwe lê dixe û dirijîne, gelekî dienire û hema di cih de serê teyrê xwe jêdike. Dema cardin tasa xwe da ber wan dilopên avê, berê wî dikeve jorîn ku çi bibîne, marekî ku mirî ew dilopê ku av dizanîbû jehra mar ji jor de dilop dikir. Piştre fêm kir ku teyrê wî nebûya dê ew ava vexara û bi wê jehrê bimira. Ew jî zaf poşman bû, lê nema dikarîbû teyrê xwe bi şûnde vegerandiya.

Û wezîr got:

- Sultanê min. Ger tu jî naxwazî tu poşman bibî ji vê fikra xwe vegere.

Li ser van gotinên wezîrê xwe ji wê ramana xwe vegeriya û heft roj û heft şevan li def û zirnê xist û qîza xwe bi wî xortê bedew re zewicand...

\section{Wezîr}

3. Kahraman Odaklı Yapısal Halk Bilimi Kuramlarına Göre Çîroka Sultan û

Çîroka Sultan û Wezîr, barındırdığı çoklu yapısı ile kahraman odaklı yapısal halk bilimi kuramlarından bazı denklikler barındırmaktadır. Anlatıda toplumsal bağ içinde düşünülecek eşkıya figürü olmadığından Eric J. Hobsbawn'ın Sosyal Haydut veya Kahraman Kalıbı'nın ilkelerinden herhangi bir denklik bulgusuna rastlanmamıştır.

\subsection{Johann Georg von Hahn'ın Aryan Kahramanı Biyografik Modeli'ne} Göre Çîroka Sultan û Wezîr

Johann Georg von Hahn'ın “Aryan Kahramanı Biyografik Modeli”, ilk zamanlarda pek ilgi görmese de İngiltere'de Alfred Nutt tarafından Kelt geleneğine başarıyla uygulanması ve özellikle Edward Tylor ve takipçilerinin çalışmaları ile gündemleşmiştir (Çobanoğlu, 2012: 214). Modelde "doğum, gençlik, dönüş ve ikinci dereceden şahıslar" kategorilerinde toplam on altı madde yer almaktadır.

Çîroka Sultan û Wezîr, “Aryan Kahramanı Biyografik Modeli”"nin “doğum” aşamasından doğrudan bir denkliğe sahip değildir. Fakat ilgi kurulabilecek durumlar söz konusudur. Modelin ilgili maddeleri şunlardır:

\section{Doğum}

1. Kahraman gayrı meşru olarak doğar. (ilgi kurulabilir.) 
Kahramanın doğumu anlatıda belirgin bir şekilde yer almaktadır. Bu nedenle anlatı ile modelin bu aşamasının ilkeleri arasında örtüşüm durumu, bu bağlamda mümkün olmaktadır. Doğum, söz konusudur ama gayrı meşru değildir.

2. Annesi ülkenin prensesidir. (Karşılık yok.)

3. Babası bir tanrı veya bir yabancıdır. (ilgi kurulabilir.)

Baba, bir yabancı olmayıp kahramanın daha sonraki serüvenine bağlı olarak yabancılık durumu ortaya çıkmaktadır.

Anlatının, modelin "gençlik" aşamasından kimi denkliklere sahip olduğu görülmektedir. İlgili maddeler ve anlatıdaki karşılıklar şunlardır:

\section{Gençlik}

1. Kahramanın yükselişinin işaretleri vardır. (Karşılık var.)

Vezir'in Sultan'a anlattığı hikâyenin kahramanı, henüz yeni doğmuşken ileride Sultan'ın kızıyla evlenecek kişi olarak takdim edilir. Bu onun yükselmesi için ileriye dönük açık bir işarettir. Yoksul bir ailenin çocuğu olması bakımından Sultan bundan hoşlanmaz ve onun için kötü bir son tasarlar. Kahramanın, kendisi için tasarlanan tehlikeli durumlardan kurtulması da aynı çerçevede bu yükselmenin işareti olarak gösterilebilir. Masalın henüz başında dinleyici veya okurlar için bu durum merak unsurunu da sağlar. Yükselmenin birtakım olumsuzluklara rağmen gerçekleşip gerçekleşmemesi arasında kalmak kurguya sürükleyicilik katar.

\section{Bu nedenle terk edilmiştir. (Karşılık var.)}

Sultan, kahraman için öngörülen kızıyla evlenecek kişi olması gerçeğinden kurtulmak ve bunun yaşanmasının önüne geçmek için onu belirsizliklere sürükler. Aslında doğrudan ölüme terk edilir. Bu Sultan için nettir. Fakat ölümün gerçekleşmesi için kahramanın suya bırakılması tasarlanan sonu muhtemel plana çeker. Bu nedenle kahramanın terk edilmesi sonraki ilkeler için bağlayıc bir yapı gösterir.

3. O, hayvanlar tarafından emzirilir. (Karşılık yok.)

4. Çocuksuz bir çoban çifti tarafından büyütülür. (Karşılık var.)

Sultan ve Vezir tarafından suya bırakılan çocuk balıkçı bir aile tarafından bulunur ve sahiplenilerek büyütülür. Aile, çoban çifti olmasa da eşdeğer konuma sahip olup balıkçı olarak anlatıda geçmektedir. Form değişikliği söz konusu olsa da kahramanın koşulları sağlayan durum örtüşmektedir. Bu ailenin çocuklarının olmadığı da anlatıda geçer. Çocuksuzluk kahramanın sahiplenilmesi ve korunması için bir nevi bir teminat olarak değerlendirilebilir. Bu kahramanın gözetilmesi gereken zamanlarda başına kötü şeylerin gelmemesi durumunu pekiştirir.

5. O, yüksek ruhlu bir gençtir. (Karşılık var.) 
Anlatıda evlat edinilen çocuğun büyüdüğü ve ailesine balık satışı konusundan yardımcı olduğu geçmektedir. Bu olumlu davranış ve gence atfedilen güzellik, güçlülük ve bilgelik vasıfları kahramanın yüksek ruhluluğuna işarettir. Herkesin balık alma konusunda kahramana yönelmesi ve onun herkesten önce balık satışını tamamlaması da yüksek ruhlu olma konusunda anlam taşımaktadır.

6. O, yabancı bir ülkede hizmet edeceği bir iş arar. (Karşılık yok.)

Anlatının, modelin “dönüş” aşamasından yalnızca bir madde ile denklik gösterdiği söylenebilir. Bunun da ilgi kurulabilecek bir karşılığa sahip olduğu görülmektedir. Modelin bu aşamadaki maddeleri şunlardır:

\section{Dönüş}

1. O, geriye muzaffer olarak döner ve tekrar yabancı ülkeye gider. (ilgi kurulabilir.)

Anlatıda kahraman, sona doğru Sultan'ın kızıyla evlenecek bir kurgu içinde resmedilir. Bu dönüş, kendisi için tasarlanan tuzaklardan kurtulması şeklinde gerçekleşir. Vezir tarafından fark edilip Sultan'a bilgi verildikten sonra kahraman kendisini büyüten aileden bedel karşılığında tekrar geri alınır. Sultan, kendisine gizli bir not vererek onu kendi diyarına gönderir. Sultan tarafından tasarlanan bu ikinci kötü sondan da Sultan'ın kızı vesilesiyle kurtulur. Bu durum, kahramanın muzaffer olmasını hazırlayan bir kurgusallık taşımaktadır.

2. O, gerçek düşmanlarını kılıçtan geçirir ve ülkeyi yönetmeğe başlar ve annesini kurtarır. (Karşılık yok.)

3. O, şehirler kurar. (Karşılık yok.)

4. Onun ölüm şekli olağanüstüdür. (Karşılık yok.)

Anlatıda ikinci dereceden şahıslar ile ilgili olarak herhangi bir denklik söz konusu değildir. İlgili maddeler şunlardır:

\section{ikinci Dereceden Şahıslar}

1. $O$, ensest ilişki nedeniyle lanetlenmiştir ve genç ölür. (Karşılık yok.)

2. O, hakarete uğrayan bir hizmetçisinin eliyle intikam için öldürülür. (Karşılık yok.)

3. O, daha genç olan kardeşini öldürür. (Karşılık yok.)

\subsection{Otto Rank'ın Kahraman Kalıbı'na Göre Çîroka Sultan û Wezîr}

Otto Rank, Kahraman Kalıbı kuramını psikanalatik ilkeler çerçevesinde yorumlamış, ev içinde baba-oğul mücadelesine dayalı olarak kahramanın gelişim 
gösterdiğini ileri sürmüştür (Çobanoğlu, 2012: 209; Hîkmet, 2015: 74). Model on iki maddeden oluşmaktadır.

Anlatı ile Otto Rank'ın “Kahraman Kalıbı” arasında bazı denklikler söz konusudur. Modelin ilgili maddeleri ve anlatının denklik durumu şöyledir:

1. Kahraman, sıra dışı bir ailenin çocuğudur. (ilgi kurulabilir.)

Anlatıda kahramanın sıra dışı bir aileden olmadığı rahatlıkla ileri sürülebilir. Fakat Sultan ve Vezir'in konumları düşünüldüğünde onlar için sıra dışılık söz konusu edilebilir. Neticede kurgu temelli edebî eserlerde karakterler veya unsurlar arasında çatışma veya farklılıkların olması gerekir. Bu durum, çoğu zaman taraflar nezdinde sıra dışılığı yahut kendinden farklı olmayı sağlayan bir rol oynar. Sultan ve Vezir'in yolu, kahramanla kendi normallerinin dışında kesişmiştir. Bu açıdan ilgili madde ile kahramanın konumu arasında ilgi kurulabilir.

2. Kahramanın babası bir kraldır. (ilgi kurulabilir.)

Kahramanın babası bir kral değildir ama Sultan tarafından gerçek ailesinden alınması ve kurgunun bu çerçevede devam ettirilmesi yapısal bir yakınlık içinde düşünülebilir. Bu ilke, kahramana seçkin bir vasıf kazandırılması açısından düşünüldüğünde metnin buna elverdiği yönünde kimi çıkarımlarda bulunmak mümkündür. Çünkü anlatıda kahraman hedefe doğru ilerlerken sonuca doğru söz konusu seçkin vasıfla bir temas durumundadır. Bu açıdan madde ile anlatı arasında dolaylı bir ilgi kurulması mümkündür.

3. Kahramanın ana rahmine düşüş şartları zordur. (Karşılık yok.)

4. Kahramanın doğumuna karşı kehanetler ve uyarılar vardır. (Karşılık var.)

Kahraman doğduktan sonra ileride Sultan'ın kızıyla evleneceği kehaneti ileri sürülür. Bu durum Sultan için bir uyarı niteliğinde algılanır. Uyarıyı yapan Vezir'dir. Nitekim anlatı ilerledikçe kahramandan kurtulduğunu düşünen Sultan'a onun ölmediği bildirilir ve böylece anlatıda kehanet/uyarı Sultan için yeniden söz konusu olur. Bu ilgi, yapısal anlamda anlatıda kahramana karşıtlığı doğuran ilk belirti olur.

\section{Kahraman, suya bir kutu içinde bırakılır. (Karşılık var.)}

Anlatıda bu madde ile doğrudan bir karşılık söz konusudur. Sultan ve Vezir'i tarafından kahraman kehanetin gerçekleşmemesi için suya bir sandık içinde bırakılır. Kurgu itibarıyla suya bırakılmanın henüz netleșmemiş bir sonu imlediği söylenebilir. Bu yapısal anlamda kahramanın yaşama olasılığını artıran bir rolde değerlendirilebilir. Sultan ve Vezir'i cephesinde kesin bir sonun hazırlandığının sanılması kurguyu sürükleyen önemli bir unsurdur.

6. Kahraman, hayvanlar veya iyi insanlar tarafından korunur. (Karşılık var.) 
Kahraman, balıkçı aile tarafından bulunur ve korunur. Büyütülen kahramanın aile tarafından sahiplenilmesi ve büyütülmesi olumluluklar içinde sunulur. Balıkçı ailenin çocuklarının olmamasının sevgi ve bağlılığı sağlayan bir rol oynadığından bahsedilebilir. Aynı zamanda bu durum, kahramanın korunmasına dair güçlü bir emare olarak görülebilir.

7. Kahramanı, dişi bir hayvan veya mütevazı bir kadın emzirir. (ilgi kurulabilir.)

Kahramanın balıkçı aile tarafından büyütülmesi, mütevazı bir kadının onu emzirdiğine yorulabilir.

8. Kahraman büyür. (Karşılık var.)

Kahramanın büyüdüğü anlatıda geçmektedir. Hatta büyüyüp kendisini yetiştiren aileye yardımcı olduğu, güzellik, çalışkanlık gibi olumlu davranışlar içinde sunulur. Anlatının başında Vezir tarafından belirtilen sonucun gerçekleşmesi için kahramanın büyümesi önemli bir adımdır.

9. Ve gerçek ailesini bulur. (Ilgi kurulabilir.)

Gerçek ailesiyle bir buluşma söz konusu değildir ama Vezir ve Sultan ile yeniden karşılaşma yaşanır. Kendisi için tasarlanan ikinci kötü sondan da Sultan'ın kızı sayesinde kurtulur. Kahramanın Sultan'ın kızıyla yollarının kesişmesi de bu anlamda ilgi kurulabilecek bir yön taşır.

10. Babasından intikamını alır. (ilgi kurulabilir.)

Sultan'ın kahramandan kurtulmak istemesine rağmen kehanetin gerçekleşmesi bu madde kapsamında değerlendirilebilir. Sultan'ın kötülükten ders çıkarması ve sözünden vazgeçmesi intikamı öteleyen bir anlamı ön plana çıkarsa da kahramanın bir zaferi söz konusudur. Anlatının başında öne sürülen kahraman ve Sultan'ın kızının evlilikleri böylece gerçekleşir ve bu da kahraman lehine bir zaferi söz konusu eder.

11. Kahraman, halk tarafından tanınır ve kabul edilir. (Karşılık var.)

Kahramanın, mektup aracılığıyla kabul edilmesi ve evlendirilmesi tanınmaya işarettir.

12. Kahraman rütbe kazanır, yükselir ve onurlanır. (Karşılık var.)

Kahramanın her şeye rağmen Sultan'ın kızı ile evlenmesi, bir yükselmenin ve onurlanmanın işareti olarak görülebilir.

\subsection{Lord Raglan'ın Geleneksel Kahraman Kuramı'na Göre Çîroka Sultan û} Wezîr

Lord Raglan'ın “Geleneksel Kahraman Kuramı”, kahramanların tarihsel bir gerçekliğinin bulunmadığı, kurmaca oldukları anlayışına dayanmakta olup kahramanın hayatını bütüncül bir şekilde ele alan kapsamlı bir modeldir 
(Çobanoğlu, 2012: 210). Yirmi iki maddeden oluşan model, dini ritüellerle de ilişkili kılınmıştır ve ilkelerinin genişletilebileceği ileri sürülmüştür (Hîkmet, 2015: 75).

Anlatı ile Lord Raglan'ın “Geleneksel Kahraman Kuramı” arasında bazı denklikler söz konusudur. Kuramın ilgili maddeleri ve anlatının denklik durumu şu şekildedir:

1. Kahramanın annesi soylu bir bakiredir. (Karşılık yok.)

2. Babası bir kraldır ve (ilgi kurulabilir.)

Bu madde, Otto Rank'ın modelinde ikinci madde ile aynı çerçevede bir karşılığa denk gelir. Anlatıda Sultan'ın bu role büründüğünden bahsedilebilir. Kral veya anlatı çerçevesinde Sultan'ın kahramana yakın bir ilişki içerisinde olması ve ona karşı bir amaç içinde kurgulanması bu ilke çerçevesinde söz konusu edilebilir.

3. Baba çoğunlukla kahramanın annesinin yakın bir akrabasıdır, fakat (Karşılık yok.)

4. Kahramanın ana rahmine düşüş şartları olağan dışıdır. (Karşılık yok.)

5. Kahraman aynı zamanda bir Tanrının oğlu olarak kabul edilir. (Karşılık yok.)

6. Kahramanın doğumu anında genellikle babası veya anne tarafından dedesi, onu öldürme girişiminde bulunulur, fakat (Karşılık var.)

Kahramanın Sultan ve Vezir tarafından doğduktan sonra bedel karşılığında ailesinden alınması ve öldürülme girişimi söz konusudur. Suya bir sandık içinde bırakılması buna denk düşer. Ayrıca anlatıda kahramanın gençlik zamanında da Sultan tarafından öldürülme planları geçmektedir.

7. Kahraman gizli bir yere gönderilir ve (Karşılık var.)

Kahraman, doğduktan sonra Sultan ve Vezir tarafından bir sandık içinde gizlice suya bırakılır. Bu durum, kahramanın bilinmeyen bir yere gönderilmesi olarak okunabilir. Kurgu itibarıla kahramanın yetişkinliğe adım atması ve ileri sürülen sonun gerçekleşmesi için aslında bir bilinmezlik olması son derece makuldür. Bilinmezlik, bu doğrultuda korunma durumunu sağlayan bir etmen olarak değerlendirilebilir. Hem kahramanı yetiştiren balıkçı aile hem de Sultan ve Vezir cephesinde bu gizlilik farklı şekillerde cereyan eder.

8. Kahraman uzak bir ülkede kendisini evlat edinen bir aile tarafından büyütülür. (Karşılık var.)

Bu madde, Hahn'ın modelinden "gençlik" dönemi için dördüncü; Otto Rank'ın modelinden ise altıncı madde ile irtibatlı olarak düşünülebilir. Anlatıda kahramanın çocukları olmayan balıkçı aile tarafından evlat edinildiği geçmektedir. 
9. Kahramanın çocukluğu hakkında bize hiçbir şey anlatılmaz, fakat (Karşılık var.)

Kahramanın çocukluk çağından bilgiler anlatıda geçmez. Onu sahiplenen ve yetiştiren aile kurguya dâhil olduktan sonra gençlik ve yetişkinlik dönemiyle ilgili gereklilikler devreye girer.

10. Kahraman yetişkinlik çağına eriştiğinde, gelecekte kral olacağı yere gider. (Karşılık var.)

Anlatıda doğrudan bir yolculuk olmasa da Vezir ve Sultan ile karşılaşma yeni bir serüvene kapı aralandığına işarettir. Anlatıda doğumla birlikte ileri sürülen şey, kahramanın Sultan'ın kızıyla evlenmesidir. Bu husus, gelecekte onu bekleyen olumlu duruma işarettir.

11. Kahraman, kral, dev veya yırtıcı bir hayvana karşı kazandığı bir zaferden sonra, (Karşılık var.)

Kahramanın Sultan'ın kızının yardımıyla da olsa kendisine kurulan tuzakları atlatarak bir zafer kazandığı görülür. Bu ilke, Hahn'ın ve Otto Rank'ın modelleriyle irtibat kurulabilecek karşılıklara sahiptir. Kazanılan zafer, kahramanın Sultan'ın tuzaklarının boşa çıkarılarak kızıyla evlenmesi ve bir paye elde etmesidir.

12. Kahraman çoğu zaman selefi olduğu kralın kızıyla evlenir ve (Karşılık var.)

Bu madde, anlatıda doğrudan bir karşılığa sahiptir. Başlangıçta ileri sürülen evlilik gerçekleşir. Anlatının hemen başlarında evlilik öngörüsü ve sona doğru bunun gerçekleşmesi, aynı zamanda kurguda motivasyonu sağlayan unsur olarak değerlendirilebilir.

13. Kahraman kral olur. (Karşılık yok.)

14. Bir süre herhangi bir olay olmaksızın hüküm sürer ve (Karşılık yok.)

15. Yeni kanunlar çıkarır fakat (Karşılık yok.)

16. Daha sonra kahraman tanrıların ve/veya halkın sevgisini kaybeder, (Karşılık yok.)

17. Tahttan ve şehirden uzaklaştırılır. (Karşılık yok.)

18. Kahraman esrarengiz bir şekilde ölümle tanışır, (Karşılık yok.)

19. Çoğunlukla bir tepenin üzerinde ölür. (Karşılık yok.)

20. Eğer varsa çocuklarından hiçbiri onun yerine tahta geçemez. (Karşılık yok.) 
21. Kahramanın vücudu gömülmez fakat buna rağmen, (Karşılık yok.)

22. Kahramanın gömülü olduğu kabul edilen bir veya daha fazla kutsal mezarı vardır. (Karşılık yok.)

\section{Sonuç}

Çiroka Sultan û Wezîr adlı Kürt anlatısı, kahraman odaklı yapısal halk bilimi kuramlarının ilkeleriyle birebir uyum göstermese de söz konusu kuramların bazı ilkeleriyle örtüşüm içerisindedir. Bu açıdan Batı anlatılarına yönelik olarak belirlenen ilkelerle örnek anlatı arasında tam bir yapısal uyumdan bahsedilemeyeceği gibi tamamen bir uzaklık da yoktur. Nitekim araştırmada dikkate alınan metin merkezli ve kahraman odaklı yapısal halk bilimi kuramlarının kimi maddeleri, doğrudan veya dolaylı ilgilerin kurulmasına olanak sunmaktadır. Anlatı, Johann Georg von Hahn'ın “Aryan Kahramanı Biyografik Modeli”'nin "doğum, gençlik, dönüş ve ikinci dereceden şahıslar" başlıkları altında bulunan toplamda on altı ilkeden yedisiyle ilintili olarak görülmüştür. Otto Rank'ın “Kahraman Kalıbı"'nda bulunan on iki ilkenin on birinin anlatıyla örtüştüğü tespit edilmiştir. Anlatının Lord Raglan'ın “Geleneksel Kahraman Kuramı”'nın yirmi iki ilkesinden ise yalnızca altısıyla uyum gösterdiği bilgisine ulaşılmıştır. Bu durumda anlatının Otto Rank'ın “Kahraman Kalıbı"'ıyla uyumunun yüksek olduğu; “Aryan Kahramanı Biyografik Modeli" ve "Geleneksel Kahraman Kuramı"'yla ise daha sınırlı bir yapı gösterdiği sonucuna ulaşılmıştır. Anlatının yapısal anlamda gösterdiği kimi özelliklerin, aynı zamanda bu kuramların maddeleri arasında bağ kuracak şekilde bir kesişim durumuna sahip olduğu anlaşılmaktadır. Bu sonuç, Kürt anlatılarından Çîroka Sultan û Wezîr'in örnekliğinde halk anlatılarının yapısal unsurlar açsından hem bazı ortaklıklara hem de özelleşmelere sahip olduğunu göstermektedir. Ortaklıkların kahramanın yaşam serüveninde "karşııık var" şeklinde işaretlenen ilkelerle belirdiği; "ilgi kurulabilir" olan durumların kısmen, "karşıllık yok" şeklinde gösterilen durumların ise ilgili kuramlar çerçevesinde tamamen özelleştiği tespit edilmiştir.

Johann Georg von Hahn'ın "Aryan Kahramanı Biyografik Modeli" çerçvesinde anlatının "doğum, gençlik, dönüş" kategorileriyle uyuştuğu ama ilkelerin tamamını taşımadığı, "ikinci dereceden şahıslar" kategorisinde de hiçbir karşılığa sahip olmadığı görülmüştür. Modelde ikinci derceden şahıslarda geçen "lanetlenmek", "genç yaşta ölmek", "hizmetçi” veya "kahramanın kardeşi" tarafından öldürülmek anlatı için söz konusu değildir. Otto Rank'ın "Kahraman Kalıbı" açısından anlatının "Kahramanın ana rahmine düşüş şartları zordur." ilkesi dışında bütün ilkelerle uyuştuğu tespit edilmiştir. Anlatıda kahramanın doğumu verilmekte ama öncesi için bu durumu güçleştirecek bir bilgi yer almamaktadır. Anlatı, “Geleneksel Kahraman Kuramı"'na göre değerlendirildiğinde ise on ikinci ilkeye kadar görece bir benzerliğin olduğu fakat bundan sonraki on madde ile benzerliğin bulunmadığı tespit edilmiştir. Bu kuram, kahramanın biyografisi açısından bütüncül bir yapı göstermektedir ve örnek anlatıda kahramanın elde 
edilen sonuçtan sonraki yaşamına yer verilmediği gözlemlenmiştir. Öte yandan Çîroka Sultan û Wezîr, bağlı masallar kategorisinde değerlendirildiği için iç içe anlatılar şeklindedir. Bu nedenle kahraman Xortê Bedew dolayımında söz konusu kuramlarla örtüşüm durumu göz önünde bulundurulmuştur. Dolayısıyla kahramanın serüveninde bu çerçevede benzemezlikler yanında anlatının yapısal anlamda başkaca farklııklar taşıdığı da söz konusudur.

\section{Kaynakça}

Bozkoyun, M. (2015). Beşek Ji Folklora Kurdî: Çîrok. Bingöl Üniversitesi Yaşayan Diller Enstitüsü Dergisi, 1 (2), 142-157.

Campbell, J. (2010). Kahramanın Sonsuz Yolculuğu. İstanbul: Kabalcı Yayınevi.

Carlyle, T. (2000). Kahramanlar. i̇stanbul: Beyaz Balina Yayınları.

Cewerî, F. (2018). Antolojîya Çîrokên Kurdî llı. İstanbul: Avesta Yayınları.

Çeliktaş, S. (2018). Tîpolojîya Lehengê Kurd Li Çarçoveya Nêrînên Joseph Campbell -Bi Mînakên Rustemê Zal Û Memê Alan-. Doktora tezi. Mardin Artuklu Üniversitesi. Mardin.

Çobanoğlu, Ö. (2012). Halk Bilimi Kuramları ve Araştırma Yöntemleri Tarihine Giriş. Ankara: Akçağ Yayınları.

Dündar, H. (2002). Vladimir propp ve masalın biçimbilimi. Milli Folklor, 7(55), 115118.

Eliade, M. (2001). Mitlerin Özellikleri. İstanbul: Om Yayınevi.

Hîkmet, B. (2015). Li Gorî Teorîyên Nûjen Nêrîneke Giștî li Ser Folklora Kurdî. Edebiyata Kurdî ya Gelêrî içinde (Ed. Ramazan Pertev) (ss. 25-109). İstanbul: Avesta Yayınları.

Keskin, N. (2019). Folklor û Edebiyata Gelêrî. İstanbul: Avesta Yayınları.

Pertev, R. (2018). Folklor û Nasnameya Kurdî ya Neteweyî (1898-1946). İstanbul: Avesta Yayınları.

Subaşı, K. (2019). Kürtçe (Kurmanci) Masalların Anlatı Tipolojisi-Tîpolojîya Vegêrana Çîrvanokên Kurdî (Kurmancî). Yayımlanmamış doktora tezi, Dicle Üniversitesi, Diyarbakır.

Tarduş, i. (2018). Taybetiyên Lehengên Tradîsyonel Di Vegotina Kurdî de, The Journal of Mesopotamian Studies, 3 (1), 57-76.

Zana, S. (2019). Folklor, Îdeoloji û Netewesazî. Folklorame, 2, 51-59. 


\section{Ek: Sultan ve Vezir'in Masalı}

Vezir'i elinden tutar ve şöyle der: "Şu tutumundan bir vazgeç, eğer beni dinlersen, sana bir sultandan bahsedeyim ki o da senin gibi hiddetlenmişti ve sonunda yaptıklarından pişmanlık duymuştu.

Sultan'ın biri, veziri ile birlikte halkın arasına karışır. Birkaç şehri gezdikten sonra akşam olur. Kapısını çaldıkları evin sahibine: verir:

“Siz misafir ağırlar mısınız?" diye sorarlar. Bunun üstüne ev sahibi cevap

- Misafirler, Tanrı'nın misafiridir. Baş göz üstüne, buyurun içeri.

Evdekiler, ne Sultan'ı ne de Vezir'ini tanır! Akşam yemeğinin ardından gecenin ilerleyen vakitlerinde yataklar serilir ve yatılır. O gece evin hanımının bir oğlu olur. Bunun üzerine, evin yeni doğan oğlunun Sultan'ın kızının kısmeti olduğu Vezir'e ayan olur. Vezir, sabah kendisine gece ayan olan bu bilgiyi Sultan'a açar:

- Gece bu evin bir oğlu oldu ve bu oğul senin kızının kısmeti olacak.

Sultan bunun üzerine hiddetlenir ve der:

- Ben, bu fakir ve muhtaç evin oğlunun damadım olmasına izin vermem.

Sultan, yeni doğan oğulun babasını çağırır ve der:

- Eğer yeni doğan oğlunu bana veririsen sana yüz altın vereceğim.

Bu pazarlık üzerine, baba eşiyle konuşur. O kadar muhtaç haldedirler ki bu isteği kabul ederler. Oğullarını yüz altın karşılığında Sultan'a veririrler. Sultan ve Vezir'i, uyuttukları çocuğu marongoza yaptırdıkları bir sandığın içine koyduktan sonra denize bırakırlar. Geri dönerlerken sultan vezirine der:

- Ben sana demedim mi, o fakir ve muhtaç oğul benim kızımla evlenemez diye.

Daha sonra şehrin birinde geçimini balık satarak sağlayan bir adam denize açılır ve sandığı görür görmez elbiselerini çıkarıp denize atlar, sandığı çıkarır. Sandığı evine götürür ve açar! Bir de ne görsünler, çok güzel bir çocuk sandığın içinde. Çocukları olmadığı için de çok mutlu olurlar. Balıkçı ve eşi, çocuğu kendi çocukları gibi sahiplenir ve büyütür. Yıllar sonra bu çocuktan çok yakışıklı, güçlü ve bilge bir genç çıkar. O, babasının avladığı balıkları alır, pazarda satar ve kazancını babasına teslim edermiş. Çok çalışkan ve bilgiliymiş, herkesten önce balıklarını satar, insanlar pazara gelip ondan balık alırlarmış. Aradan çok zaman geçer, birgün Sultan'ın vezirinin yolu pazara düşer. Gözüne bu genç ilişince hemen oracıkta onu tanır. Döner Sultan'a der:

- Ben, Allah adına yemin ederim ki bugün denize bıraktığımız o genci pazarda gördüm. Bu söz üzerine gencin ardına düşüp kaldığı eve giderler. Kapıyı 
çalarlar, kapı açılır ve içeri girerler. Ev sahibi onları tanımaz ve sorar: "Siz kimsiniz ve ne istiyorsunuz?" Bu soru üzerine Sultan cevaplar:

- Biz, senin büyüttüğün genç için geldik, o senin oğlun değil, biz onu senden satın almaya geldik. Bize ver onu, bakım ve emekleriniz karşılığında size iyi bir ödül vereceğim. Bunun üzerine balıkçı durumu anlar ve eşini çağırır.

Adam, eşine gencin gerçekten onların oğlu olmadığını söyler, gönlü el vermese de ödülü kabul eder ve gencin elini tutup Sultan'a verir. Altınlar verilir.

Sultan bir yazı yazar ve gencin eline tutuşturarak der:

- Sen, biz varıncaya kadar bu mesajı bu adrese götür.

Yiğit ve yakışıklı genç, Sultan'ın mesajı için büyük şehrin yolunu tutar. Günlerce yürür ve yorgun bir şekilde şehrin önlerine varır, orada bir üzüm bağındaki ağacın altında duraklar. Ağacın gölgesinde oturur ve uyayakalır.

O arada Sultan'ın kızı da saraydan çıkar ve bahçelerde gezinir. Bu sırada bir adamın ağacın gölgesinde uyuduğunu fark eder. Yanına varır, bir de ne görsün! Ayın on dördü gibi yiğit bir genç, alımlı ve yakışıklı. Ona âşık olur. Elindeki mesajı görür ve yavaşça alıp açar. Sultan'ın kızı babasının yazısını tanır, babası mesajda şöyle demiştir:

- Cellatlara emrimdir: Eğer bu genç yanınıza gelirse, hiçbir şey sormadan kellesini alın.

Bu ferman üzerine, Sultan'ın kızı hayıflanır ve içinden “Acaba babam bu yiğit gençten ne istemiş olabilir?” Sultan'ın kızı, içinde şunu dediği başka bir mesaj yazar:

- Cellatlara emrimdir: Eğer bu genç yanınıza gelirse, ben şehre varmadan kızımla onu evlendirin.

Ve o babasının mesajı yerine kendi yazdığını gencin eline tutuşturur ve döner saraya... Peşinden yakışıklı genç, uykusunu iyice alır ve adresin yolunu tutar, kapıya varır ve mesajı adrese teslim eder. Mesaja bakılır bakılmaz genç hızlıca saraya götürülür, Sultan'ın kızıyla tanıştırılır ve evlilik hazırlıklarına başlanır.

Sultan, huzurlu bir şekilde şehre vardığında bir de ne görsün! Kızının elleri o gencin elinde ve onlar için hazırlık yapılmış, evleniyorlar. Bunun üzerine hiddetlenir ve der:

- Ben onu kendi ellerimle öldüreceğim! Onun kızımla evlenmemesi için yemin ettim.

Bu kızgınlığı üzerine Vezir’i elinden tutar ve şöyle der: “Şu tutumundan bir vazgeç, eğer beni dinlersen, sana bir Sultan'dan bahsedeyim ki o da senin gibi hiddetlenmiş ve sonunda yaptıklarından pişmanlık duymuş. Yapılmadık kötü iş bırakmayan Sultan, bu hatalarından geri dönmüş. 
Bu senin başına gelmesin der ve ekler:

- Sultan'ım bir ülkede senin gibi bir sultan varmış, bir akşam kuşun biri gagasında taşıdığı körpe fidanı onun avlusuna bırakmış. Sultan da o körpe fidanı dikmiş, sabah olunca avluya çıkıp görmüş ki büyümüş ve iri elmalar vermiş. Hizmetçiye seslenmiş ve bir elma getir, bakalım nedir bu iş, demiş. Hizmetçi gitmiş, ağacın altındaki bir elmayı eğilip yerden almış ve Sultan'a getirmiş. Sultan, yaşı bir kadını çağırtmış, elmayı ona yedirmiş ve hemen oracıkta yaşlı kadın ölmüş. Bunun üzerine Sultan çok kızmış ve kuşun gelmesini kollamış. Akşama doğru kuş gelmiş ve Sultan kuşu öldürmüş! Sultan düşünmüş ve hizmetçiyi çağırmış, o elmayı nereden getirdiğini sormuş. Bu soruya hizmetçi “Ben o elmayı ağacın dibinde gördüm ve aldım." cevabını vermiş. Sultan hizmetçiye tekrardan sabah git ve elmayı ağacın dalında koparıp getir demiş. Sabah olmuş, elma dalından koparılmış, yaşı ı birine verilmiş. Yaşlı olan elmayı yediği gibi gençleşmiş, on yedi yaşındaki bir genç gibi olmuş. Bunun üzerine Sultan kuşu öldürmekten dolayı çok pişman olmuş. Sultanım sen eğer damadını öldürürsen işte böyle pişman olacaksın.

Sultan, bununla da ikna olmaz. Vezir'i başka bir masal anlatır:

- Sultanım bir gün biri ava çıkar. Dağlarda çöllerde epey gezinir. Çok yorulur, susar ama hiçbir yerde su bulamaz. Bir kayanın önüne varır, kayadan suyun damladığını fark eder, hemen bir tas heybesinden çıkarır ve damlaların önüne tutar! İçmeye yeltendiğinde kuşu kanadını tasa vurup o suyu döker.

Kuşu peşinden birkaç kez daha kanadını vurup suyu döker, çok öfkelenir ve hemen oracıkta kuşun kafasını koparır. Tekrar tası damlaların önüne tuttuğunda, gözü yukarı ilişir ki ne görsün, su damlası sandığı ölü bir yılanın yukarıdan damlayan zehriymiş. Ardından anlar ki kuşu olmasaydı o suyu içecekti ve o zehirden ölecekti. Çok pişman olur ama kuşunu geri getirmeye gücü yetmez.

Ve Vezir der:

- Sultanım. Eğer sen de istemezsen pişman olacaksın, bu fikrinden vazgeç.

Vezir'inin anlattıklarından sonra Sultan bu tutumundan vazgeçer ve yedi gün yedi gece def ve zurna çalar, kızını o yakışıklı genç ile evlendirir... 